\title{
PROGASTRIN-LIKE IMMUNOREACTIVITY IN PORCINE ANTRUM: IDENTIFICATION AND CHARACTERIZATION WITH REGION-SPECIFIC ANTISERA
}

\author{
Kentaro Sugano and Tadataka Yamada \\ Department of Internal Medicine, \\ IIniversity of Michigan Medical Center, \\ Ann Arbor, Michigan
}

Received October 26, 1984

In an effort to identify and characterize precursors of gastrin in tissues, we generated region-specific antisera against a synthetic progastrin peptide, Tyr-Gly-Trp-Met-Asp-Phe-Gly-Arg-Arg (GL9), as deduced from the nucleotide sequence of gastrin mRNA. This antisera did not cross-react with gastrin or progastrin peptides with shorter carboxyl-terminal extensions. Progastrin-like immunoreactivity (PGLI) was measured in porcine antrum at a concentration of $6.8 \pm 1.2 \mathrm{pmol} / \mathrm{g}$ wet weight (mean $\pm S E, n=5$ ), or roughly $0.2 \%$ of that of gastrin. On Sephadex G50 chromatography, a major peak of PGLI was eluted as a slightly larger molecule than gastrin heptadecapeptide (G17) but possessed the same $\mathrm{N}$-terminal immunoreactivity. These findings suggest that G17 may be formed by processing of a carboxyl-terminally extended precursor as an alternative to cleavage of big gastrin (G34). 1985 Academic Press, Inc.

Gastrin has a variety of physiological actions in the gut, the most important of which appears to be stimulation of acid secretion (1). Recently the structure of progastrin has been deduced from the nucleotide sequence of mRNA cloned from hog antrum and human Zollinger-Ellison tumors $(2,3)$, however, no direct evidence is available for the existence of progastrin in tissues. Thus, we developed antisera that recognize the proposed progastrin sequence specifically at the site where the processing step for creating the biologically important carboxyl-terminal amide must take place. With this antisera, we identified and characterized progastrin-like immuonoreactivity (PGLI) in porcine stomach. The biochemical characteristics of PGLI provide insight into the mechanism of gastrin biosynthesis. 


\section{MATERIALS AND METHODS}

Peptides: The peptides with specific progastrin sequences utilized in this study are indicated on Table 1. GL7, GL9, and GL11 were custom-synthesized by Peninsula Laboratories (Belmont, CA). GL8 was prepared from GL11 by tryptic digestion and Asp-Phe-Gly-Arg-Arg was made from GL9 by CNBr cleavage. G17 (human) and Arg-Arg were obtained from Research Plus (Bayonne, NJ) and G34 and hexagastrin (G6) were kindly provided by Dr. John Walsh (Los Angeles, CA). G113 (human) was a product of Bachem (Torrance, CA). Dynorph in A 1-7 (porcine), human adrenocorticotropic hormone (ACTH 1-24), neurotens in 1-13, and bombesin were purchased from Peninsula Laboratories. Porcine pancreatic glucagon was obtained from Eli Lilly (Indianapolis, IN). Cholecystokinin octapeptide (CCK8) and desamido CCK8 were provided by Dr. Travis Solomon (Columbia, MO). Somatostatin 14 was supplied by Diamalt (Munich, West Germany).

Tissue Extraction: Small pieces of fresh porcine gastric tissue (12g) were boiled for $10 \mathrm{~min}$ in distilled water (10 $\mathrm{ml} / \mathrm{g}$ wet weight) and then homogenized with a Polytron tissue homogenizer. Tissue homogenates were ultracentrifuged at $100,000 \times \mathrm{g}$ for $30 \mathrm{~min}$, and the supernatant was stored at $-20^{\circ}$ until further analysis.

Antibody Generation: GL9 was conjugated to bovine serum albumin using glutaraldehyde with a molar ratio of peptide to protein of 10 to 1. GL9-prote in conjugate was emulsified with Freunds complete adjuvant (Difco, Detroit, MI) and administered subcutaneously to New Zealand white rabbits. Identical booster injections were given in monthly intervals.

Radioimmunoassay: GL9 was labeled with ${ }^{125}$ I using the standard chloramine T method (4). The label was purified by chromatography on a Sephadex G-10 (Pharmacia, Picataway, NJ) column $(1.0 \times 20 \mathrm{~cm})$ equilibrated with $0.1 \mathrm{M}$ ammonium acetate $\mathrm{pH} 5.0 / 0.1 \%$ BSA followed by chromatography on a CM-cel1u1ose (CM-52, Whatman, Kent, U.K.) column $(1.5 \times 10 \mathrm{~cm})$ equilibrated with the same buffer and eluted with a linear gradient of ammonium acetate $(0.1 \mathrm{M}$ to $1.0 \mathrm{M})$. Standard assay mixtures contained $125 \mathrm{I}-\mathrm{GL} 9$, various amounts of standard peptide or unknown sample and antibody ( $A b 8207$, final dilution of 1 to 50,000 ) in $1 \mathrm{ml}$ of sodium barbital buffer $\mathrm{pH} 8.6$ containing $0.1 \%$ BSA, 2mM EDTA and $0.02 \% \mathrm{NaN}_{3}$. After incubation for 18-20 hrs at $4^{\circ} \mathrm{C}$, free and bound radioactivity were separated using dextrancoated charcoal. Amino-terminal G17 assays using antibody 1295 and carboxyl-terminal gastrin radioimunoassay using antibodies 5135 and 1611 were performed using methods previously described $(5,6)$. These gastrin antibodies were kindly supplied by Dr. John Walsh.

TABLE 1

STRUCTURE OF GASTRIN, PROGASTRIN AND SYNTHETIC PROGASTRIN PEPTIDES

$\begin{array}{ll}-- \text { Tyr-Giy-Trp-Met-Gly-Phe-Gly-Arg-Arg-Ser-Ala-Gly--- } & \text { Progastrin } \\ \text { Tyr-Gly-Trp-Met-Asp-Phe-Gly-Arg-Arg-Ser-Ala } & \text { GL11 } \\ \text { Tyr-Gly-Trp-Met-Asp-Phe-Gly-Arg-Arg } & \text { GL } 9 \\ \text { Tyr-Gly-Trp-Met-Asp-Phe-Gly-Arg } & \text { GL } 8 \\ \text { Tyr-Gly-Trp-Met-Asp-Phe-Gly } & \text { GL } 7 \\ \text {---Tyr-Gly-Trp-Met-Asp-Phe-NH } & \text { Gastrin }\end{array}$


Affinity Chromatography: Purified gamma globulin (120 mg) from antisera 8207 was coupled to Affi-Gel 10 (Bio-Rad Laboratories, Richmond, $(A)$ according to methods described in the manufacturer's bulletin (Technical Bulletin 1085). The affinity beads adsorbed both GL9 and GL11 but completely excluded GL7, G17 and G 1-13. Recovery of PGLI on affinity chromatography ranged from 85-100\%.

Gel-Filtration Column Chromatography: Affinity purified materials were lyophilized, reconstituted in $0.2 \mathrm{M} \mathrm{Tris-HCl} \mathrm{pH} 8.0$ containing $2 \mathrm{mM}$ EDTA, and applied to a Sephadex G-50 (superfine) column (1.5 x $75 \mathrm{~cm}$ ) equilibrated and eluted in sodium barbital buffer $\mathrm{pH} 8.6$ containing $2 \mathrm{mM}$ EDTA. The column was calibrated with blue dextran, G34 (human), G17 and the salt elution peak.

\section{RESULTS AND DISCUSSION}

Competitive binding curves for radioimunoassay with Ab 8207 using ${ }^{125}$ I-GL.9 as label are shown in Fig. 1. The carboxyl terminal Arg-Arg structure appeared to be critically important for binding to this antibody. Loss of one arginine residue at the carboxyl terminus of GL9 (i.e. GL8) decreased binding to $0.1 \%$ and virtually no binding was observed with GL7 which lacks both arginines. However, other amino acids in the structure of GL9 were also necessary for binding because neither the dipeptide Arg-Arg nor peptides containing Arg-Arg at the carboxyl terminus or elsewhere in their sequence (neurotensin, ACTH, glucagon or dynorph in A 1-7),

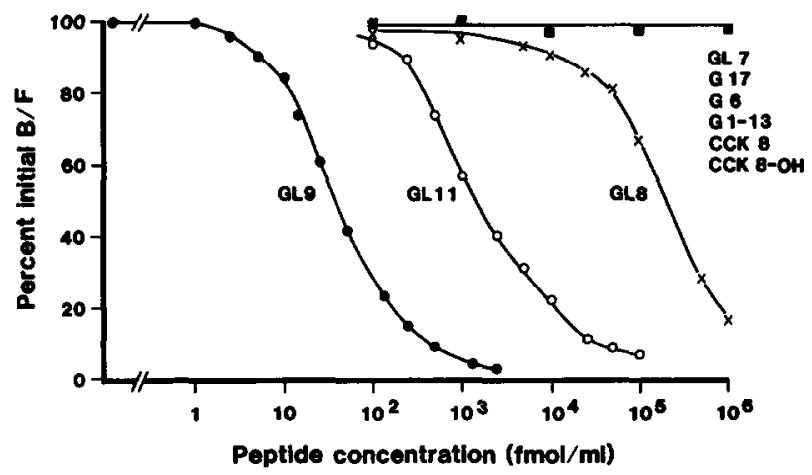

Fig. 1: Competitive bindjgg curves for antibody 8207 . The ratio of antibody-bound and free $125_{I-G L 9}$ (B/F) are expressed as a percentage of maximal B/F. Fifty percent inhibition of tracer binding to antibody occurred at a concentration of $41 \pm 4 \mathrm{fmol} / \mathrm{ml}$ (mean $\pm S E$, $n=5$ ) of GL9. The intra-assay coefficients of variation for samples containing 10,50 , and $125 \mathrm{fmol} / \mathrm{mI}$ of $G L 9$ were $11.6,2.4$, and $6.6 \%(n=5)$, respectively. The inter-assay coefficients of variations for these same samples were $18.0,3.4$, and $3.7 \%$ (when measured in 4 consecutive assays). 
cross-reacted with the antibody. The antibody cross-reacted 3-5\% with Asp-Phe-Gly-Arg-Arg but the label displacement curve with this peptide was not parallel to the one obtained with GL9. Extension at the C-terminus by two more amino acids (GL11) diminished binding but the degree of cross-reactivity was much greater than that observed with GL7 or GL8. Other peptides including amidated forms of gastrin (G34, G17, G6), the amino terminal tri-decapeptide of G17 (G1-13), CCK8, desamido CCK8 (CCK 8-OH), somatostatin and bombesin all failed to cross-react with our antibody at the highest concentration tested (1 nmol/ml). From our detailed specificity studies it is evident that the antigenic requirement for recognition involves a portion of the carboxyl terminal sequence of gastrin as well as an extension of at least three amino acids as predicted from the nucleotide sequence of gastrin mRNA. Therefore, we termed material immunoassayable with our antibody as progastrin-like immunoreactivity (PGLI).

In support of this assumption, PGLI was demonstrated almost exclusively in the antral mucosa, matching the distribution of gastrin (Table 2). Furthermore, our preliminary immunohistochemical studies showed that PGLI was localized specifically to antral Gcells (7). The level of PGLI, however, was much lower than that of gastrin, comprising only $0.2 \%$ of total gastrin immunoreactivity. Dilutions of PGLI in antral extracts displaced ${ }^{125}$ I-GL9 bound to our

TABLE 2

GASTRIN AND PROGASTRIN-LIKE IMMUNOREACTIVITY (PGLI) CONCENTRATIONS IN PORCINE STOMACH

\begin{tabular}{lcc}
\hline \multicolumn{1}{c}{ TISSUE } & $\begin{array}{c}\text { PGLI } \\
\text { (Ab 8207) }\end{array}$ & $\begin{array}{c}\text { GASTRIN } \\
\text { (Ab 5135) }\end{array}$ \\
\hline Cardiac Mucosa & $0.4 \pm 0.1(3)^{*}$ & $0.7 \pm 0.1 \quad(3)$ \\
Fundic Mucosa & $0.3 \pm 0.2(3)$ & $18.5 \pm 15.6(3)$ \\
Antral Mucosa & $6.8 \pm 1.2(5)$ & $2800 \pm 942 \quad(5)$ \\
Muscle Layer & $0.2 \pm 0.1(3)$ & $20.9 \pm 9.4 \quad(3)$ \\
\hline
\end{tabular}

${ }^{\text {}_{\mathrm{pmo}}}$ 1/g wet weight, mean \pm SE, $\mathrm{n}$ indicated in parentheses 

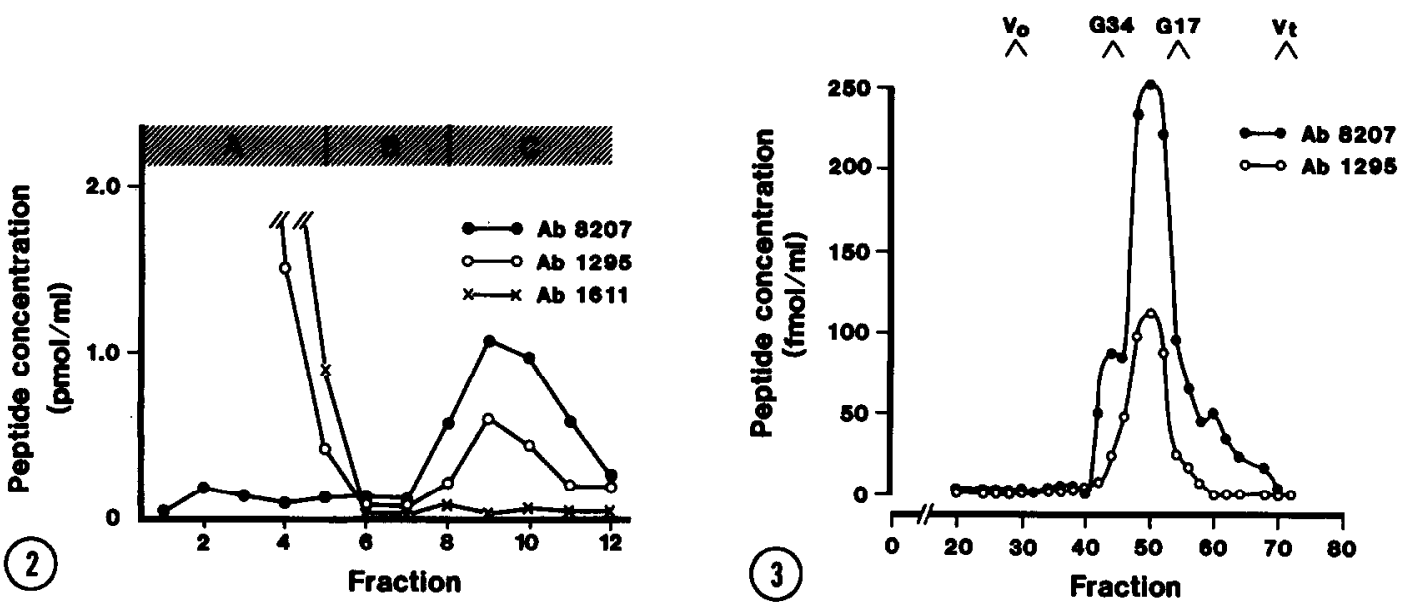

Fig. 2: Chromatography of porcine antral extracts on progastrin affinity beads. Bofling water extracts of porcine antral mucosa were applied to Affi-Gel 10 beads linked to antibody 8207 . The column was washed with 3 column volumes of phosphate buffer (A) followed by ammonium acetate buffer (B) and eluted with $2 \%$ TFA (C). Fractions were radioimmunoassayed with antibodies 8207,1295 and 1611 for PGLI, amino-terminal G17 immunoreactivity and carboxylterminal gastrin, respectively.

Fig. 3: Gel filtration of porcine antral extracts purified by affinity chromatography. The materials purified by affinity chromatography (see Fig. 2) were applied to a Sephadex G-50 (superfine) column as described in the text. Both amino-terminal G17 and PGLI activity were measured by radioimmunoassay using antibodies 1295 and 8207 , respectively. Since all the carboxy terminal gastrin immunoreactivity was removed by previous affinity chromatography none was detected in the eluted fractions.

antibody in parallel with the standard curve for radioimunoassay. As depicted in Fig. 2, PGLI was completely adsorbed to an affinity column made with antibody 8207 whereas all the gastrin-like immunoreactivity, measured with a carboxyl-terminal specific assay, appeared in the column void. In contrast, a substantial fraction of amino-terminal G17-like immunoreactivity was co-eluted with PGLI using TFA. These data indicate that some of the PGLI in antral extracts has an amino terminal structure immunochemically similar to G17. When affinity purified PGLI was applied to Sephadex G-50 chromatography, a major peak appeared as a slightly larger molecule than G17 and possessed amino-terminal G17-like immunoreactivity (Fig. 3), suggesting that its molecular structure consisted of G17 with a carboxyl-terminal extension in place of the amide moiety. 
The existence of such a molecule suggests the 617 may be formed from this molecule through carboxyl terminal processing, although prevailing theories $(8,9)$ suggest that $G 17$ is solely derived from the cleavage of $\mathrm{G} 34$.

\section{ACKNOWLEDGEMENTS}

We gratefully acknowledge the technical assistance of Mimi Takami and the secretarial assistance of Lori Ennis. This study was supported by NIH Grants AM17328, AM34306, and AM33500. Dr. Sugano was a recipient of a Silbert International Scholarship.

\section{REFERENCES}

1. Walsh, J.H. (1981) in Physiology of the Gastrointestinal Tract (Johnson, L.R. ed.) pp. 59-144. Raven Press, New York

2. Yoo, 0.J., Powe11, C.T. and Agarwa1, K.J. (1982) Proc. Nat1. Acad. Sci. USA, 79, 1049-1053.

3. Boe 1, E., Vaust, J., Norris, F, Norris, K., Wild, A., Rehfeld, J.F. and Marcker, K.A. (1983) Proc. Nat1. Acad. Sci. USA, 80, 2866-2869.

4. Greenwood, F.C., Hunter W.M. and Glover, J.S. (1963) Biochem. J., 89, 114-123.

5. Dockray, G.F. and Walsh, J.H. (1975) Gastroenterology, 68, 222230.

6. Rosenquist, G.L. and Walsh, J.H. (1980) In Gastrointestinal Hormones (Glass, G.B.J. ed), pp. 769-795. Raven Press, New York.

7. Sugano, K., Aponte, G. and Yamada, T. (1984) Clin. Res., 32, 287 (Abstract).

8. Rehfeld, J.F. (1981) Am. J. Physiol. 240, G255-G266.

9. Dockray, G.J, Vaillant, C. and Hopkins, C.R. (1978) Nature, $273,770-772$. 